\title{
Performance Comparison Between Copper Cables and Fiber Optic in Data Transfer on Banjarmasin Weather Temperature Conditions
}

\author{
Husnul Khatimi ${ }^{1, *}$, Eka Setya Wijaya ${ }^{1}$, Andreyan Rizky Baskara ${ }^{1}$, and Yuslena Sari $^{1}$ \\ ${ }^{1}$ Information Technology, Faculty of Engineering, Lambung Mangkurat University, Indonesia
}

\begin{abstract}
Copper wire cable and fiber optic cable are two communication media that are widely used in building data communication networks in today's modern era. For network administrators, choosing the right type of cable to build a network is a must. Air temperature is one of the external factors that can affect the performance of network equipment. This paper provides a comparative analysis of the differences in performance between the use of fiber optic cables and copper wire cables which are capable of transferring data of 1 Gigabit per second. Performance measurement analysis includes the ability to transfer data from both media such as latency, throughput, and packet loss. For testing latency and throughput is done by sending as many as 65,000 data 30 times for each media. Whereas for packet loss testing is done by sending 10,000 data within 1 minute using test bandwidth on the Mikrotik router. From the test results, it can be seen that there is an effect of temperature changes on the performance of copper wire cable and fiber optic cable. The higher the air temperature, the packet loss, and latency will increase. As for the throughput value, the temperature only affects the throughput value on fiber optic cable and does not affect throughput on the copper wire cable.
\end{abstract}

Key words: Copper wire, fiber optic, latency, packet loss, throughput.

\section{Introduction}

Cable-based networks promise better performance compared to using wireless media. This makes the cable a choice of communication media options that can be used to connect between computer devices. Cables commonly used today on computer networks are copper wire cables with various models and types that have their weaknesses and advantages.

Copper is a relatively soft, reddish metal that conducts heat and electricity very well.[1] The electrical properties of copper wire create resistance and interference. The further communication signals travel the more they are weakened by the electrical properties associated with the copper cable. Electrical, resistance within the copper medium slows down the signal or flow of current. The electrical properties of copper wire are the key factors that limit communication transmission speed and distance.[2]

There are two primary types of cables containing copper wire used for communication: Twisted Pair and Coaxial. Coaxial cable types are currently being abandoned because the

* Corresponding author: hkhatimi@ulm.ac.id 
ports for BNC connectors used are rarely found on computing devices or network devices such as switches and routers. Installing a network with a coaxial cable is difficult and requires extreme expertise especially in creating or installing connectors.[3]

\subsection{Twisted Pair}

Twisted pair cable is the most widely used cable for transmitting data packets on a computer network. Inside this cable there are four pairs of copper wire that are twisted into one, each wire is given a different color from one another to facilitate the cable installation process on the connector. Twisted pair cables are divided into three types of cables namely Shielded Twisted Pair (STP), foiled twisted pair (FTP), and Unshielded Twisted Pair (UTP). Of the three types of twisted pair cables, STP can process data transfer that is fast enough and can be used for outdoor conditions. The STP cable has an additional protective layer of aluminum foil on each pair of wires which provides good strength and durability from any interference from electromagnetic waves.[4]. STP cable structure can be seen in fig. 1.

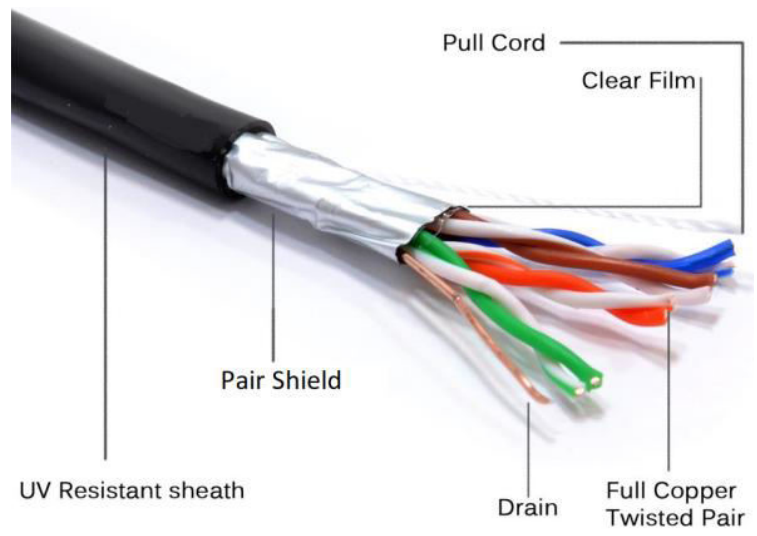

Fig. 1. Twisted Pair Cable

\subsection{Fiber Optic}

Fiber optics, also called optical fibers, are thin strands of glass that carry pulses of light (frequently infrared light) across long distances. Fiber optic channels are usually immune to common RF interference and can transmit an incredibly high amount of data very quickly.[5] Fiber optic chain works in the following manner. At one end, the fiber cable is connected to a transmitter. The transmitter converts the electronic pulses into light pulses and sends the optical signal through the fiber cable. At the other end, the fiber cable is plugged into a receiver which decodes the optical signal back into digital pulses.[6] Because it does not conduct electrical signals, fiber optic cable is resistant to interference making it very stable in its use. This cable is very suitable for use in areas with a lot of electromagnetic interference. Fiber optic cable has two transmission modes namely Single Mode which utilizes laser light as the transmission medium and Multi-Mode which uses light-emitting diode (LED). Fiber optic cable can be seen in Fig. 2. 


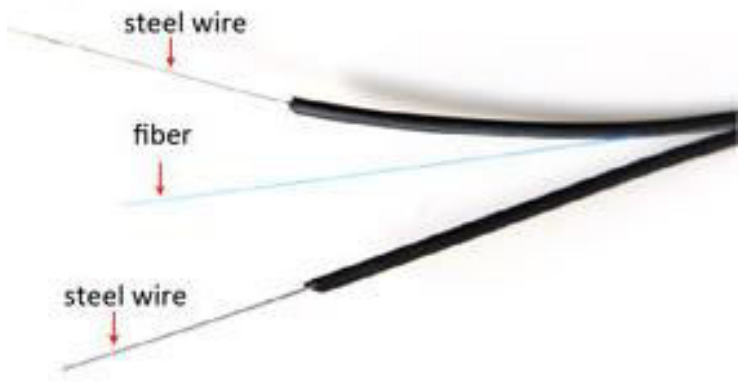

Fig. 2. Fiber Optic Cable.

Single Mode Fiber optic cable memiliki ukuran core yang jauh lebih kecil dibandingkan dengan Multi Mode yaitu hanya 9 microns dan hanya memiliki satu jalur penghantar cahaya. Single Mode Fiber optic memiliki beberapa kelebihan dibandingkan dengan tipe Multi Mode yaitu dapat membawa data dengan bandwidth yang lebih besar. Single Mode dapat membawa data dengan lebih cepat dan 50 kali lebih jauh sehingga kabel ini banyak digunakan oleh banyak institusi dan perusahaan saat ini.

\subsection{Computer Network Performance}

In general, the performance measurement parameters of a network are throughput, delay or response time and packet loss. Although there are still other parameters. Computer network performance may vary due to several problems, such as the problem of packet loss, delay (latency) and throughput, which can make a big enough effect for many applications. For example, voice communications (such as IP Telephony or VoIP) and video streaming can make users frustrated when the application is streamed data packets over the network bandwidth is not enough, or with a delay that cannot be predicted. Having regard to packet loss, delay (latency) and throughput can be predicted and matched with the needs of the applications that are used in the existing network.[7]

\subsubsection{Throughput}

Throughput is the rate of effective data transfer measured in bps (bits per second). The value of throughput is calculated from the total number of successful arrival packages that are observed at the destination during a certain time interval divided by the duration of the time interval. Throughput despite having the same formula unit and the bandwidth, but the throughput is on describing the actual bandwidth at a certain time and on certain conditions and internet network that is used to download a file with a certain size. Some of the factors that determine the bandwidth and throughput are network devices, network topology, the number of network users, electric induction and weather [11].

\subsubsection{Delay}

Delay or Latency is the time delay caused by the transmission from one point to another point which becomes the goal. Delay in TCP/IP networks can be classified as follows:

- Packetization Delay

Delay caused by the time required for the process of the formation of the IP packet of information users. This delay only occurs once, namely in resources. 
- Queuing Delay

This delay is caused by the processing time required by the routers in handling packet transmission queue along the network.

- Delay Propogasi

Delay Propogasi is in the process of traveling information during transmission media, such as SDH, optic or copper, which causes the delay, which is called the propagation delay.

- Transmission Delay

Transmission Delay is the time it takes a packet to traverse a medium. Transmission delay is determined by the speed of the media and the size of the data packet.

- Processing Delay

Processing Delay is the time required by a network device to see the route, change the header and task switching.

To changes in the latency can be caused by the quality of the network components (cable/router/switch), serialization delay, routing, and switching latencies, and queuing and buffer management.[10] The quality of network components are factors that affect the propagation delay. Propagation delay is the time required information/data to travel at the speed of light in a medium of communication from the source to the destination. In free space, the speed of light is approximately $3 \times 108 \mathrm{~m} / \mathrm{sec}$. The speed of light is lower in other media such as copper wire or fiber optic cable. Speed reduction caused by the type of transmission is called velocity factor (VF). Copper wire cable and fiber optic cable has a factor of nearly the same speed. Speed fiber optic cable is usually about $70 \%$ of the speed of light while the copper wires vary from $40 \%$ to $80 \%$ depending on the construction.[7]

\subsubsection{Packet Loss}

Packet Loss is the failure of the transmission of IP packets to its destination. Packet loss is caused by a variety of possibilities, including:

- Congestion caused because of excessive queues in the network

- Node, work exceeds the capacity of the buffer

- Memory is limited to nodes

- Policing or control of the network to ensure that the amount of traffic that flows to the amount of bandwidth, if the amount of traffic that flows in the network exceeds the bandwidth capacity, policing control will remove the excess of existing traffic.

Packet loss occurs when packets are broken and discarded, or when the capacity of the network components exceeds the limit, which results in the packet is discarded. Packets can be damaged as they move across the wide area network medium. This type of damage is detected in the process of "checksum." The checksum is the number of bits that are mathematically calculated by the sender and added to each packet. Recipients also calculate the checksum and comparing the calculated value with the value received by the package. If the received and the calculated checksum does not match, the receiver discards the packet.[8]

\subsection{Weather Temperature in Banjarmasin}

Under the Köppen climate classification, Banjarmasin features a tropical wet and dry climate. Temperatures are relatively consistent throughout the year, averaging about 27 degrees Celsius, and the city has no real dry season. However, Banjarmasin has noticeably wetter and drier times of the year. November through May forms the wettest part of the 
year with monthly precipitation of 200 millimeters $(7.9$ in) or more per month. June through October is drier with monthly precipitation of about 120 millimeters (4.7 in) per month. Banjarmasin on average sees just under 2,600 millimeters (100 in) of rain per year.[12] Wired computer network performance is typically very reliable when there are no other environmental factors; however, when we add environmental stress, it can become very difficult to maintain reliable electrical performance. Environmental stress results from the physical area in which the cables are used and exposed. Extreme temperatures affect cable materials, with low temperatures making them brittle and high temperatures causing them to become very soft. Like extreme temperatures, extreme pressures can have a significant impact on cables.[13]. For this reason, it is necessary to research to compare the performance of the two types of cables commonly used for weather conditions, especially in Banjarmasin. The results of this study are expected to be a reference for network administrators in institutions and companies providing data communication services.

\section{Material and Methods}

In this study, we used two Mikrotik routers with Wireless Router RB962UiGS-5HacT2HnT HAP-AC (Fig. 3) and adding SFP-1G-BD-SM Microbits to be used as a fiber optic cable port for the experiment.
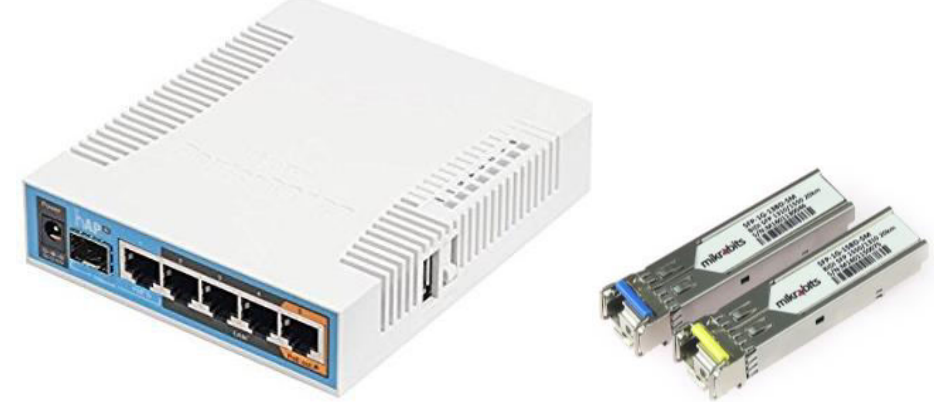

Fig. 3. Mikrotik routers and Standart Fiber Optic Port (SFP)

The cables used in this experiment are outdoor cat. 6 UTP cables and single-core optical drop wire fiber cables with a length of 100 meters as shown in Fig. 4

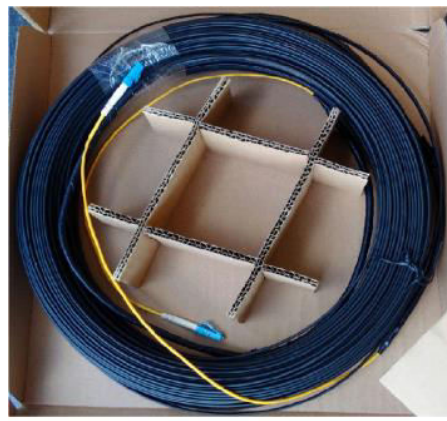

Drop Wire Single Core Fiber Optic Cable

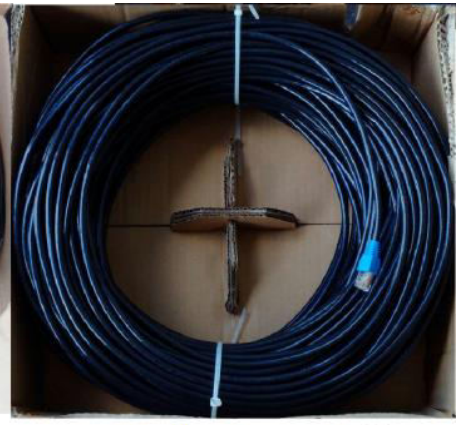

STP Outdoor Category 6 Cable

Fig. 4. Fiber Optic Cable and Copper wire cable used in this research

The experiment carried out by stretching the cable outdoor so it will directly expose to the sun and outdoor weather temperature as shown in installation process on Fig. 5. Each end of both cables connected to the Mikrotik router in Fig. 6. 


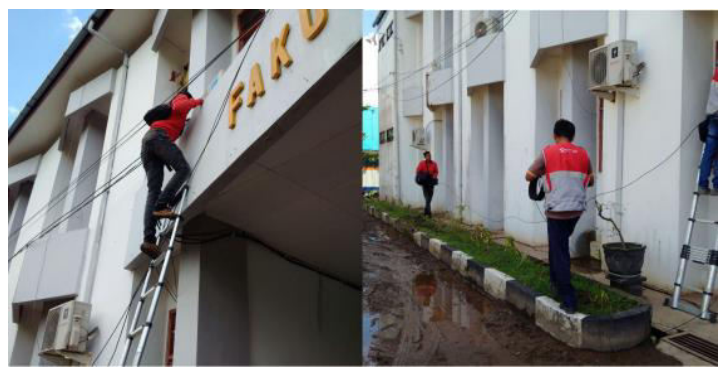

Fig. 5. Cable installation process

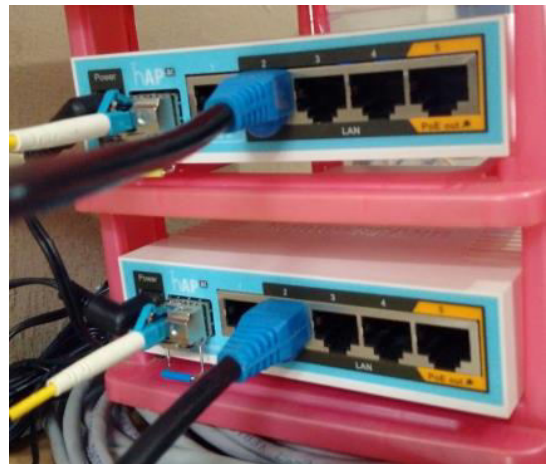

Fig. 6. Network Connection Set Using Mikrotik Router in this research

The scenario of this experiment is the router will be sending some data packets to both cables to test the performance of each wire. The results will be recorded in the router log and will be sent automatically via email every 5 hours for observation. We used the Bandwidth Test on Mikrotik to find the value of throughput and packet loss during the experiment. Bandwidth Test set to push 10,000 data packets using UDP protocol with $1000 \mathrm{Mbps}(1 \mathrm{Gbps})$ data transfer rate in 60 seconds duration. The configuration script for packet loss test is as follow.

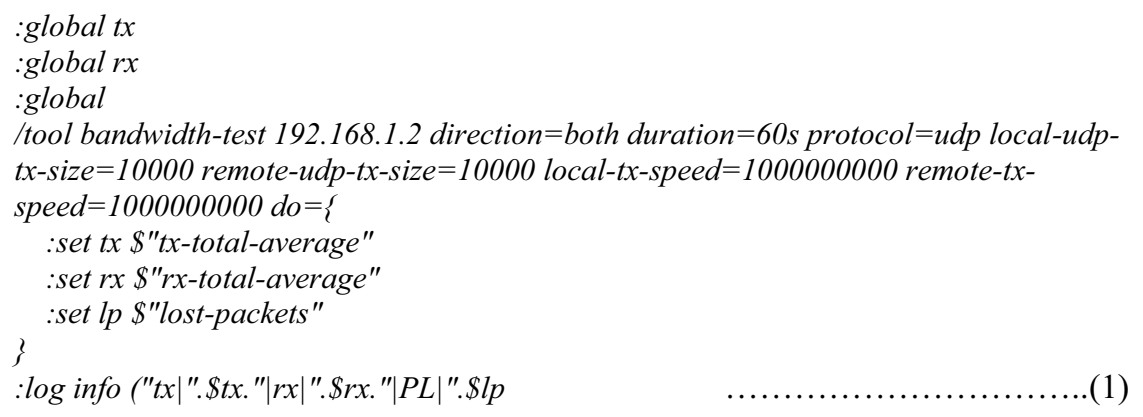

While tools to find the value of Delay/latency using Ping on Mikrotik. Ping is one of the most commonly used and known commands. Administration utility used to test whether a particular host is reachable across an Internet Protocol (IP) network and to measure the round-trip time for packets sent from the local host to a destination host, including the local host's interfaces. Ping uses Internet Control Message Protocol (ICMP) protocol for echo response and echo request. Ping sends ICMP echo request packets to the target host and waits for an ICMP response. Ping output displays the minimum, average and maximum times used for a ping packet to find a specified system and return.[9] 
Ping set to 65,000 data packets and performed 30 times during the experiment. The configuration script for delay/latency loss test is as follow.

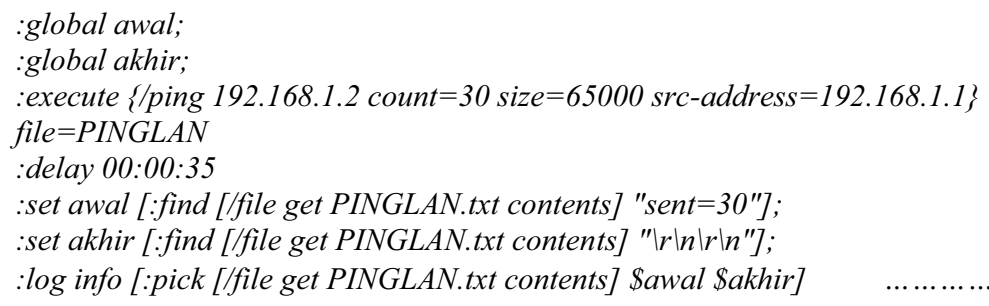

Data collection was conducted from May to June 2018. The data obtained are the network parameters of fiber optic cable and copper wire cable to changing weather conditions every day. This data will be analyzed and compared to see the performance between the two cables.

\section{Result and Discussion}

\subsection{Packet Loss}

From the results of data processing between the comparison between changes in air temperature and the number of packet loss recorded in the Mikrotik log, the results can be seen from Table 1.

Table 1. Test results for Packets Loss on temperature changes

\begin{tabular}{|c|r|r|}
\hline \multirow{2}{*}{ Temperature $\left({ }^{\mathbf{}} \mathbf{C}\right)$} & \multicolumn{2}{|c|}{ Packet Loss (data) } \\
\cline { 2 - 3 } & \multicolumn{1}{|c|}{$\begin{array}{c}\text { Copper wire } \\
\text { cable }\end{array}$} & \multicolumn{1}{c|}{ Fiber Optic } \\
\hline 22.77 & 614 & 367 \\
\hline 23.33 & 579.8333 & 338.5 \\
\hline 23.88 & 588.5 & 332.125 \\
\hline 24.44 & 571.4615 & 350.2308 \\
\hline 25 & 577.7692 & 339.9231 \\
\hline 25.55 & 567.125 & 335.375 \\
\hline 26.11 & 593.5714 & 325.5714 \\
\hline 26.66 & 671.75 & 664.25 \\
\hline 27.22 & 775 & 1324 \\
\hline 28.33 & 764.3333 & 970.6667 \\
\hline 28.88 & 793.1667 & 1008.167 \\
\hline 29.44 & 775 & 878.7778 \\
\hline 30 & 998.75 & 914.6667 \\
\hline 30.55 & 833.2143 & 1072 \\
\hline 31.11 & 885.4286 & 873.8571 \\
\hline 31.66 & 798.5 & 1224.5 \\
\hline 32.22 & 768 & 1248.333 \\
\hline
\end{tabular}

From Table 1 can be seen that there is an increasing number of packet loss along with the increase in air temperature. On copper wire cable, the number of packet loss increases gradually, while in fiber optic cable, the increase in temperature increases the number of packet loss significantly. To make it easier to understand the changes that occur, the data is displayed graphically as shown in Fig. Seven below. 


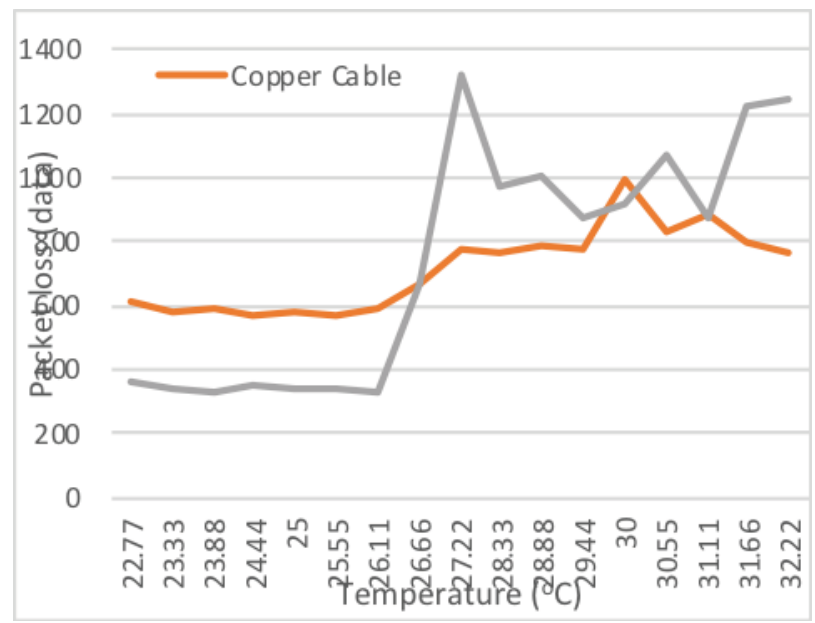

Fig. 7. Comparison of packet loss on copper wire cable and fiber optic to changes in air temperature

The increasing amount of packet loss on the fiber optic cable does not significantly affect performance due to the speed and amount of data that can pass packets per second (throughput) is much larger than the copper wire cable.

\subsection{Delay (latency)}

From the results of testing of the delay/latency, it is clear that the value of latency on fiber optic cable is far better than that of copper wire cable as can be seen on Table 2 .

Table 2. Test results for Delay/Latency on temperature changes

\begin{tabular}{|c|r|r|}
\hline \multirow{2}{*}{$\begin{array}{c}\text { Temperature } \\
\left({ }^{\circ} \mathbf{C}\right)\end{array}$} & \multicolumn{2}{|c|}{ Delay/Latency (ms) } \\
\cline { 2 - 3 } & Copper wire cable & Fiber Optic \\
\hline 22.77 & 13 & 3 \\
\hline 23.33 & 13 & 3 \\
\hline 23.88 & 13 & 3 \\
\hline 24.44 & 13 & 3 \\
\hline 25 & 12.95833333 & 3 \\
\hline 25.55 & 13 & 3 \\
\hline 26.11 & 13 & 3 \\
\hline 26.66 & 13.95833333 & 4.239583333 \\
\hline 27.22 & 14 & 4.791666667 \\
\hline 28.33 & 14.56944444 & 5.430555556 \\
\hline 28.88 & 14.1125 & 4.429292929 \\
\hline 29.44 & 14.2962963 & 4.844017094 \\
\hline 30 & 13.46722222 & 4.412563131 \\
\hline 30.55 & 13.72988095 & 4.503695182 \\
\hline 31.11 & 12.58333333 & 5.160714286 \\
\hline 31.66 & 14.125 & 4.747596154 \\
\hline 32.22 & 14.20833333 & 4.162037037 \\
\hline
\end{tabular}

Changes in air temperature affect increasing the value of delay / latency which has the effect of slowing down data transfer, both on copper cable and on fiber optic cable. This can be seen in the following Fig. 8 . 


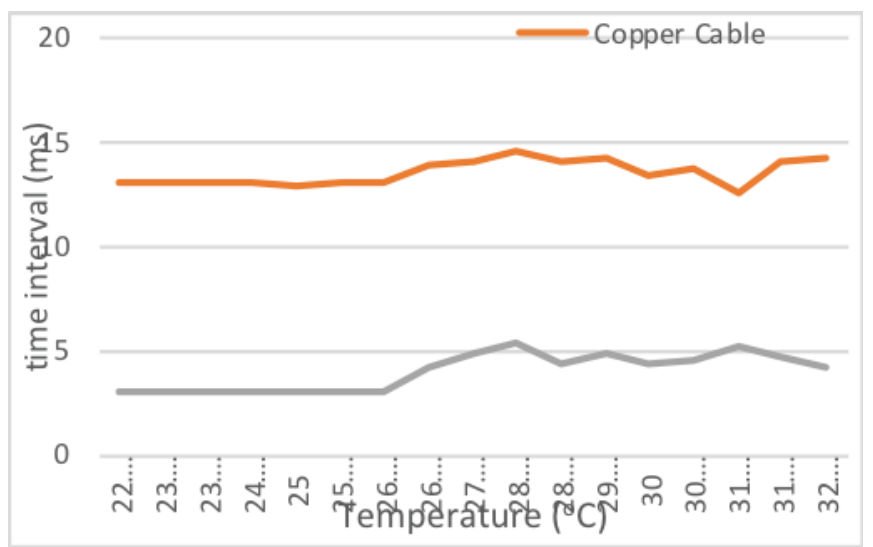

Fig. 8. Comparison of delay/latency on copper wire cable and fiber optic to changes in air temperature

\subsection{Throughput}

From the test results of the throughput, showed that the optical fiber could transfer data each second is much greater than copper wire cable as shown in Table 3.

Table 3. Test results for Throughput on temperature changes

\begin{tabular}{|c|r|r|}
\hline \multirow{2}{*}{ Temperature $\left({ }^{\mathbf{}} \mathbf{C}\right)$} & Throughput (bit per second) \\
\cline { 2 - 3 } & Copper wire cable & \multicolumn{1}{|c|}{ Fiber Optic } \\
\hline 22.77 & 83854536 & 380639688 \\
\hline 23.33 & 83849301.33 & 387037132 \\
\hline 23.88 & 83859905 & 414605419 \\
\hline 24.44 & 83844900.92 & 385743475.1 \\
\hline 25 & 83849025.23 & 380224227.1 \\
\hline 25.55 & 83843093 & 387203844 \\
\hline 26.11 & 83844485.71 & 397578138.3 \\
\hline 26.66 & 83017294 & 364111012 \\
\hline 27.22 & 76943184 & 338985456 \\
\hline 28.33 & 82369400 & 346106789.3 \\
\hline 28.88 & 81993060 & 332863700 \\
\hline 29.44 & 79425919.11 & 338530934.2 \\
\hline 30 & 82557101.33 & 310621420 \\
\hline 30.55 & 82497646.29 & 328555924.6 \\
\hline 31.11 & 122451400 & 311401265.1 \\
\hline 31.66 & 82573316 & 338916624 \\
\hline 32.22 & 82664650.67 & 344502490.7 \\
\hline \multicolumn{3}{|c}{} \\
\hline
\end{tabular}

Changes in temperature turned out to affect fiber optic cable. The higher the air temperature, the smaller the throughput value, which means that with increasing air temperature, the ability of the fiber optic cable to transfer data every second will decrease. On copper wire cable, changes in air temperature do not affect the throughput value. This can be seen in the following graph of Fig. 9 


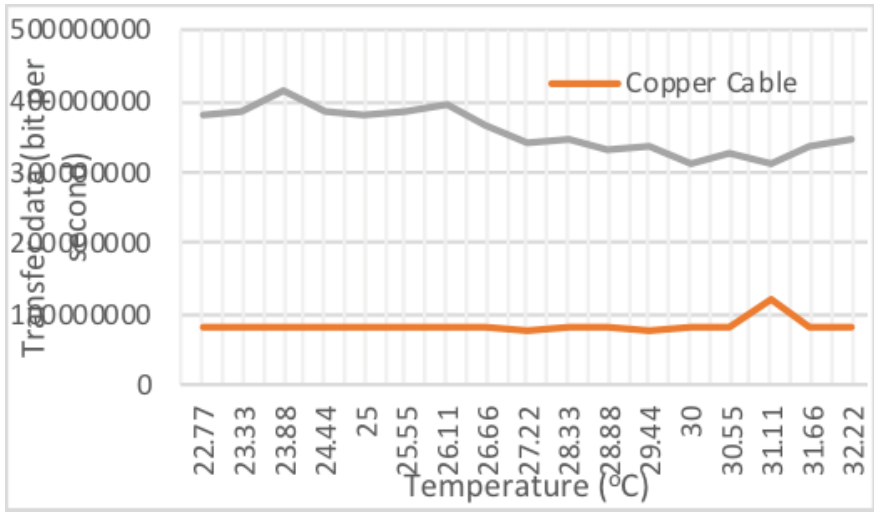

Fig. 9. Comparison of throughput on copper wire cable and fiber optic to changes in air temperature

\section{Conclusion}

This study compares the performance of copper wire cable and fiber optics to in transferring data under outdoor weather condition. We performed the experiment by observing packet loss, latency, and throughput parameters. The results of the experiment show that fiber optic performance is more superior to copper wire cable both regarding packet loss, latency or throughput at a distance of 100 meters. Meanwhile, temperature increase greatly affects the value of delay/latency and packet loss on both cables. The higher the temperature, the greater the value of delay/latency and the number of packet loss. Whereas for the throughput value on fiber optic cable, there is a decrease when the temperature is higher, but for copper cable, the change in air temperature that occurs does not affect the throughput value. This is shown by the ability of copper wire cable in sending the amount of data packets every second which tends to be constant even though the air temperature increases.

\section{References}

1. C. Woodford, "Copper: Introduction to the chemical element," 2017. [Online]. Available: https://www.explainthatstuff.com/copper.html.

2. S. Leader, "Chapter 2. Fundamentals of Telecommunications," in Telecommunications Handbook for Transportation Professionals: The Basics of Telecommunications, Washington: U.S. Department of Transportation, 2017, p. 23.

3. D. R. Winkelman, "Chapter 4. Cabling," in An Educator's Guide to School Network, Florida: Florida Center for Instructional Technology College of Education, University of South Florida, 2013.

4. Z. H. A. Abba Mohammed, Suleiman Babani, "A COMPARATIVE ANALYSIS OF THE DIFFERENCES BETWEEN FIBER OPTIC AND COPPER CABLES IN COMMUNICATION SYSTEM," in Proceedings of TheIRES 4th International Conference, 2015.

5. Wikibooks, "Communication mediums," 2017. [Online]. Available: https://en.m.wikibooks.org/wiki/Communication_mediums.

6. R. A. McDoulett, "Fiber Optics Wiring in Oklahoma," 2016. [Online]. Available: http://teamraceco.com/services/fiber-optics/. 
7. K. M. and A. A. Winarno Sugeng, Jazi Eko Istiyanto, "The Impact of QoS Changes towards Network Performance," Int. J. Comput. Networks Commun. Secur., p. 48, 2015.

8. G. M, "Impact of Packet Loss on BC/DR Deployments," sycamore lane north Illinois, 2010.

9. MikroTik, "Manual: Tools/Ping," $2017 . \quad$ [Online]. Available: https://wiki.mikrotik.com/wiki/Manual:Tools/Ping.

10. O. Networks, "What is Network Latency and Why Does It Matter?," USA, 2015.

11. E. S. Dewo, "Bandwidth dan Throughput," Jakarta, 2003.

12. Wikipedia, "Banjarmasin," $2017 . \quad$ [Online]. Available: https://en.wikipedia.org/wiki/Banjarmasin.

13. W. Paper, "Improving Cable Performance in Harsh Environments," California, 2013. 